\title{
Risk predictors for hospital readmission in a low socio-economic and underserved population
}

\author{
Tyler Couch ${ }^{1}$, Matthew Peterson ${ }^{1}$, Rodney G. Bowden*1, Grant B. Morgan ${ }^{1}$, Jackson Griggs ${ }^{2}$, Ronald L. Wilson ${ }^{3}$ \\ ${ }^{1}$ Baylor University, United States \\ ${ }^{2}$ Family Medicine, Family Health Center, United States \\ ${ }^{3}$ Internal Medicine, Baylor Scott \& White, United States
}

Received: December 5, 2017

Accepted: January 21, $2018 \quad$ Online Published: January 25, 2018

DOI: $10.5430 /$ jha.v7n1p27

URL: https://doi.org/10.5430/jha.v7n1p27

\begin{abstract}
Objective: Hospital readmissions are significant and potentially preventable sources of healthcare cost in the United States. The Affordable Care Act (ACA) establishes the Hospital Readmissions Reduction Program (HRRP) in an attempt to reduce readmissions by penalizing institutions whose 30-day readmission rates are above the national average. The current study examines demographic and clinical variables associated with early hospital readmission in a low socioeconomic status, underserved population.

Methods: A secondary data analysis was conducted of 2,536 patients from the acute primary care facilities who were hospitalized. Age, sex, race, ethnicity, smoking status, systolic blood pressure, diastolic blood pressure, body temperature, pulse rate, and days to follow up visit were analyzed in a sample of 2,536 hospitalized patients at or below $200 \%$ of federal poverty guidelines in Central Texas to determine association with risk of 0-30- (30), 31-60- (60) and 61-90- (90) day all-cause readmission.

Results: Multinomial statistical analysis found pulse rate was associated with 30-, 60-, and 90-day readmission as compared to a control group. Days to follow-up were associated with decreased risk of readmission in all groups, and passive smoking status was associated with decreased risk of 90-day readmission as compared to a control group.

Conclusions: Results offer healthcare providers with tools for potentially identifying patients at elevated risk for readmission in a disadvantaged population and suggest further investigation of other clinical and laboratory variables as predictors of readmission risk.
\end{abstract}

Key Words: Hospital readmission, Low SES, 30-day readmission, 60-day readmission, 90-day readmission

\section{INTRODUCTION}

For decades, the United States has faced what many consider a healthcare crisis characterized by escalating costs and expanding coverage gaps. Between 1990 and 2008, national healthcare spending increased by an average of $7.2 \%$ annually, ${ }^{[1]}$ and by $201018 \%$ of U.S. residents under the age of 18 lacked any form of health insurance coverage. ${ }^{[2]}$ The Patient Protection and Affordable Care Act (ACA) was passed by
Congress in 2010 to address inflating costs, coverage gaps, and attempt to increase the overall quality of care through several regulatory measures. One area of focus for the ACA in improving healthcare delivery has been the reduction of excessive hospital readmissions. It has long been postulated that hospital readmissions represent an unnecessary cost burden to national healthcare delivery. ${ }^{[3]}$ One report estimates that nearly $\$ 12$ billion of the $\$ 17.5$ billion spent annually on

\footnotetext{
*Correspondence: Rodney G. Bowden; Email: Rodney_Bowden@baylor.edu; Address: Baylor University, One Bear Place \# 97303, Waco, TX,
} United States. 
readmissions in the United States are related to potentially preventable readmissions. ${ }^{[4]}$ In addition to representing a significant cost burden, unnecessary readmissions have also come to be reported in recent years as an indicator of poor quality of care during a patient's initial hospital encounter. ${ }^{[5]}$

In an effort to curb unnecessary and costly readmissions, the ACA established the Hospital Readmissions Reduction Program (HRRP). Under the initial provisions of the HRRP, which took effect in 2013, the Center for Medicare and Medicaid Services (CMS) monitored the 30-day all cause hospital readmission rate for Medicare patients receiving an initial diagnosis of acute myocardial infarction (AMI), heart failure $(\mathrm{HF})$, or pneumonia $(\mathrm{PN})$. Institutions whose readmission rates fell above the national average were subject to reductions in Medicare and Medicaid payments of up to $1 \%{ }^{[6]}$ For the 2015 fiscal year, the provisions of the HRRP were updated to include patients diagnosed with chronic obstructive pulmonary disease (COPD) or undergoing total knee or total hip arthroplasty (TKA/THA). ${ }^{[6]}$ Additionally, the HRRP penalty cap was raised to $3 \%$ of CMS payments. ${ }^{[7]}$ Regardless of an individual's Medicare status, hospital readmissions represent a significant healthcare cost and act as an important measure for quality of care administered by hospitals.

The expanding regulatory measures and penalties of the HRRP have created within healthcare institutions an increased focus on finding measures for reducing readmissions that are both effective and cost efficient. ${ }^{[8]}$ One strategy that has demonstrated promise is the use of readily collected clinical and demographic variables to identify patients at an elevated risk of experiencing early readmission. ${ }^{\left[{ }^{12} 12\right]}$ Most variables that have been proposed as viable risk predictors are already collected in the course of patient care, and are thus relatively cost efficient to analyze. Furthermore, the identification of at-risk patients could allow healthcare providers to work closely with such patients to improve quality of care and discharge strategy, thus minimizing the likelihood of an unforeseen readmission.

While the potential benefit of using readily collected clinical variables to identify patients at risk of early readmission has been commented on within the literature, there exists some uncertainty as to which variables might serve as useful predictors of readmission risk. Common variables found in the literature include demographic data such as age, race, ethnicity, sex, and socioeconomic status. Clinical variables such as blood pressure, body temperature, BMI, smoking status, and pulse rate make up a second category of interest. Finally, days between hospital encounter and follow-up visit have also received attention from prior researchers. ${ }^{[9-11]}$

While multiple studies have examined the relationship of clinical/demographic variables, follow-up time, and early readmission, few have reported on a socioeconomically disadvantaged population. There exists a good deal of evidence that low socioeconomic status (SES) patients are at an increased risk of experiencing early readmission, ${ }^{[10,13]}$ and that safety net institutions experience greater penalties under the HRRP than hospitals serving primarily non-disadvantaged populations. ${ }^{[14-16]}$ Recent studies have suggested that the addition of COPD to the diagnoses included in the calculation of readmission penalties will only further harm hospitals serving large numbers of low SES patients. ${ }^{[17,18]}$ Given the increasing penalties levied on institutions serving socioeconomically disadvantaged populations, the evaluation of relevant predictor variables for readmission in high-risk patients within low SES population has become an important topic for investigation. The purpose of the current study was to examine risk factors associated with 0-30- (30), 31-60(60), and 61-90- (90) day all-cause hospital readmission in an underserved, socioeconomically disadvantaged patient population.

\section{Methods}

\subsection{Population overview and setting of study}

Data were obtained from patients at 12 Federally Qualified Health Centers throughout Central Texas that serve patients whose annual income is $200 \%$ or more below federal poverty guidelines. These centers offered acute primary care services, defined by the World Health Organization to "include all preventive, curative, rehabilitative, or palliative actions, whether oriented towards individuals or populations, whose primary purpose is to improve health and whose effectiveness largely depends on time-sensitive and, frequently, rapid intervention". [19] The study examined 2,536 patients from the acute primary care facilities who were hospitalized for any reason between January 1, 2006 and October 1, 2013. The total sample included 1,803 (71.1\%) females and 733 (28.9\%) males. The majority of patients belonged to an ethnic or racial minority group (32.1\% Black/African American, $25.8 \%$ Hispanic or Latino, $42.1 \%$ White/Not Hispanic). The average age of participants in the study was 44.81 years $(\sigma=$ 18.06 years).

\subsection{Data collection}

Patient data were obtained from the Epic electronic health records system of the primary care facilities under study. The demographic variables collected include age, sex, race, ethnicity, and smoking status. Ethnicity and race were selfreported by patients using preselected options based on federal government classification standards. Smoking was also self-reported, allowing for choice between the options of current smoker, former smoker who has quit, non-smoker who 
lives with smoker, never smoked, or choose not to answer. During the initial hospital encounter BMI, systolic blood pressure, diastolic blood pressure, temperature, and pulse rate were recorded as the first values obtained by healthcare professionals. The follow-up time was recorded at the patient's follow-up visit to a primary care facility. Patients admitted more than once were only included in the group of their first readmission period. Variables were selected based on a physician panel and review of the literature. Data were encrypted and made devoid of patient names or other identifying information, pursuant to the IRB approval of the host university.

\subsection{Statistical analysis}

Descriptive analysis of the data was performed to yield frequency distributions for the categorical variables under study and means and standard deviations for the quantitative variables examined. Patients were then divided into groups based on their readmission status of 30-, 60-, 90- day readmission or control (no readmission within 180 days). A multinomial regression analysis using the generalized logit link function was performed to compare the 30-, 60-, and 90-day readmission groups to the control group experiencing no readmission within 180 days. Loglinear analysis of the k-way contingency table was also considered but ultimately decided against because loglinear analysis is based on the joint distribution of all modeled variables. Multinomial regression is based on the conditional distribution of the readmission status of each patient given the set of included predictor variables. Therefore, multinomial regression was selected because it is consistent with the purpose of the study. Odds ratios and their associated confidence intervals were calculated to determine the risk of readmission associated with each variable under study. Data analysis was conducted using the SAS statistical software program.

\section{Results}

Patients in the study were primarily female $(71.1 \%)$ belonging to an ethnic or racial minority group $(32.1 \%$ Black/African American, 25.8\% Hispanic or Latino, 42.1\% White/Not Hispanic). The average age of the study participants was 44.81 years ( $\sigma=18.06$ years). Frequency distributions of sex, race/ethnicity, and smoking status are presented for each of the readmission groups in Table 1. Minimum, maximum, mean, and standard deviation of age, days to follow up visit, BMI, diastolic and systolic blood pressure, body temperature, and pulse rate for the sample are presented in Table 2.
Table 1. Frequency distributions of categorical variables for readmission groups

\begin{tabular}{|c|c|c|c|}
\hline \multicolumn{2}{|c|}{ Readmission Group } & \multirow[t]{2}{*}{ Frequency } & \multirow[t]{2}{*}{ Percent } \\
\hline \multirow{16}{*}{$\begin{array}{l}0-30 \text { days } \\
(\mathrm{N}=635)\end{array}$} & Sex & & \\
\hline & Female & 451 & 71 \\
\hline & Male & 184 & 29 \\
\hline & Total & 635 & 100 \\
\hline & Race/Ethnicity & & \\
\hline & Black/African American & 180 & 28.3 \\
\hline & Hispanic or Latino & 261 & 41.1 \\
\hline & White, Not Hispanic & 261 & 30.6 \\
\hline & Total & 635 & 100 \\
\hline & Smoking Status & & \\
\hline & Never Smoked & 295 & 46.5 \\
\hline & Passive Smoker & 19 & 3 \\
\hline & Quit Smoking & 123 & 19.4 \\
\hline & Current Smoker & 149 & 23.5 \\
\hline & No Response & 49 & 7.7 \\
\hline & Total & 635 & 100 \\
\hline \multirow{16}{*}{$\begin{array}{l}31-60 \text { days } \\
(\mathrm{N}=368)\end{array}$} & Sex & & \\
\hline & Female & 270 & 73.4 \\
\hline & Male & 98 & 26.6 \\
\hline & Total & 368 & 100 \\
\hline & Race/Ethnicity & & \\
\hline & Black/African American & 116 & 31.5 \\
\hline & Hispanic or Latino & 94 & 25.5 \\
\hline & White, Not Hispanic & 158 & 42.9 \\
\hline & Total & 368 & 100 \\
\hline & Smoking Status & & \\
\hline & Never Smoked & 162 & 44 \\
\hline & Passive Smoker & 14 & 3.8 \\
\hline & Quit Smoking & 64 & 17.4 \\
\hline & Current Smoker & 99 & 26.9 \\
\hline & No Response & 29 & 7.9 \\
\hline & Total & 368 & 100 \\
\hline \multirow{16}{*}{$\begin{array}{l}61-90 \text { days } \\
(\mathrm{N}=262)\end{array}$} & Sex & & \\
\hline & Female & 201 & 76.7 \\
\hline & Male & 61 & 23.3 \\
\hline & Total & 262 & 100 \\
\hline & Race/Ethnicity & & \\
\hline & Black/African American & 94 & 35.9 \\
\hline & Hispanic or Latino & 54 & 20.6 \\
\hline & White, Not Hispanic & 114 & 43.5 \\
\hline & Total & 262 & 100 \\
\hline & Smoking Status & & \\
\hline & Never Smoked & 131 & 50 \\
\hline & Passive Smoker & 2 & 0.8 \\
\hline & Quit Smoking & 40 & 15.3 \\
\hline & Current Smoker & 69 & 26.3 \\
\hline & No Response & 20 & 7.6 \\
\hline & Total & 262 & 100 \\
\hline \multirow{16}{*}{$\begin{array}{l}\text { Control } \\
(>180 \text { days }) \\
(\mathrm{N}=1,271)\end{array}$} & Sex & & \\
\hline & Female & 881 & 69.3 \\
\hline & Male & 390 & 30.7 \\
\hline & Total & 1271 & 100 \\
\hline & Ethnicity & & \\
\hline & Black/African American & 425 & 33.4 \\
\hline & Hispanic or Latino & 312 & 24.5 \\
\hline & White, Not Hispanic & 534 & 42 \\
\hline & Total & 1271 & 100 \\
\hline & Smoking Status & & \\
\hline & Never Smoked & 533 & 41.9 \\
\hline & Passive Smoker & 46 & 3.6 \\
\hline & Quit Smoking & 243 & 19.1 \\
\hline & Current Smoker & 394 & 31 \\
\hline & No Response & 55 & 4.3 \\
\hline & Total & 1271 & 100 \\
\hline
\end{tabular}


Table 2. Descriptive statistics for variables collected from total sample

\begin{tabular}{lllll}
\hline Variable & Minimum & Maximum & Mean & Std. Deviation \\
\hline Age & 18 & 101 & 44.81 & 18.06 \\
Days to Follow Up & 1 & 336 & 21.99 & 31.436 \\
BMI & 3 & 91 & 31.41 & 9.39 \\
Diastolic Blood Pressure & 24 & 135 & 76.39 & 12.341 \\
Systolic Blood Pressure & 72 & 250 & 128.2 & 20.421 \\
Temperature & 95.2 & 103 & 98.0 & 0.693 \\
Pulse Rate & 32 & 160 & 84.14 & 15.637 \\
\hline
\end{tabular}

Of the 2,536 patients included in the study, 635 (25.0\% of the total sample) experienced a readmission within 30 days of initial hospital encounter, 368 ( $14.5 \%$ of the total sample) experienced a readmission between 31 and 60 days, and 262 $(10.3 \%)$ experienced a readmission between 61 and 90 days. 1,271 patients ( $50.1 \%$ of the total sample) did not experience a readmission within 180 days of their discharge. Patients admitted more than once were only included in the group, with the corresponding variables, of their first readmission period. A multinomial analysis was employed to compare the 30-, 60-, and 90-day readmission groups to the group that experienced no readmission within 180 days using odds ratios with $95 \%$ confidence intervals. The results of this analysis are presented in Table 3 .

Elevated pulse rate was a predictor of increased readmission risk in all three readmission groups examined in our study $(0-30$ days: odds ratio $=1.008,95 \%$ confidence interval $=$ $[1.001,1.015] ; 31-60$ days: $\mathrm{OR}=1.012,95 \% \mathrm{CI}=[1.004$, $1.020]$; 61-90 days: $\mathrm{OR}=1.013,95 \% \mathrm{CI}=[1.004,1.022]$ ) as a continuous variable. Increased days between initial hospital encounter and follow-up visit at a primary care facility were found to be associated with lower risk of readmission within 30,60 , and 90 days when compared to patients who were not readmitted within 180 days ( $0-30$ days: $\mathrm{OR}=0.939,95 \% \mathrm{CI}$ $=[0.930,0.949] ; 31-60$ days: $\mathrm{OR}=0.970,95 \% \mathrm{CI}=[0.962$, 0.978]; 61-90 days: $\mathrm{OR}=0.986,95 \% \mathrm{CI}=[0.980,0.992]$ ). Status as a passive smoker was also found to be associated with lower readmission risk between 60 and 90 days when compared to patients who did not experience readmission within 180 days $(\mathrm{OR}=0.179,95 \% \mathrm{CI}=0.073,0.751)$.

\section{Discussion}

The purpose of the current study was to examine risk factors associated with 30-, 60-, and 90-day all-cause hospital readmission in an underserved, socioeconomically disadvantaged patient population. Results from our study discovered pulse rate was associated with increased risk of 30-, 60-, and 90-day all-cause readmission, while days to follow up were associated with decreased readmission risk at 30,60, and 90 days, and passive smoking was associated with decreased risk in only the 90-day readmission group. All other variables tested were not established as significant predictors of elevated readmission risk in the current study.

Elevated pulse rate was a predictor of increased readmission risk in all readmission groups examined in our study. Since pulse rate acts as surrogate for cardiorespiratory fitness and is determined by autonomic nervous system inputs and circulating hormones, ${ }^{[20]}$ pulse rate might be a strong marker of overall health and therefore an indicator of hospital readmission likelihood. Examination of the relationship between pulse rate and readmission risk within the scientific community has to this point been sparse. In their 2012 study of ICU patients at four different institutions, Fialho et al. reported elevated pulse rate to be associated with increased likelihood of readmission to the ICU within 72 hours of discharge. ${ }^{[21]}$ The study authors note that elevated pulse rate may be indicative of other cardiopulmonary conditions that may lead to eventual readmission. Examination of pulse rate as a readmission predictor in patient populations beyond the ICU has until this point shown little association with readmission risk. Both Krumholz et al. and Eapen et al. found no association between pulse rate and early hospital readmission. ${ }^{[11,22]}$ Our study finding which suggests that pulse rate is a predictor of 30,60, and 90 day readmission is a novel finding. Our finding may be due to the study being conducted in a socioeconomically disadvantaged population. As Fialho et al. notes, elevated pulse rate may accompany cardiovascular and respiratory diseases. ${ }^{[21]}$ It is generally well understood that patients from poverty and the underserved experience worse health outcomes from cardiorespiratory disease than their more economically stable peers. ${ }^{[23]}$ Any disease associated with elevated pulse rate in a disadvantaged population, then, may be more likely to result in an adverse health outcome (such as early readmission) than if that disease were encountered in the patient populations examined in previous studies concerning the effects of pulse rate. It should be noted that pulse rate can be highly variable and may be subject to fluctuations based on time of day, condition at the first hospital encounter, disease state and condition, and other variables. 
Table 3. Readmission risk associated with variables of study

\begin{tabular}{|c|c|c|c|c|c|}
\hline \multirow{2}{*}{ Readmission Group } & \multirow{2}{*}{ Variable } & \multirow{2}{*}{ Odds Ratio } & \multicolumn{3}{|c|}{ 95\% Confidence Interval } \\
\hline & & & Lower Bound & Upper Bound & $p$-value \\
\hline \multirow{13}{*}{$0-30$ days $(\mathrm{N}=635)$} & Age & 0.995 & 0.989 & 1.001 & .129 \\
\hline & BMI & 0.994 & 0.983 & 1.006 & .311 \\
\hline & Diastolic Blood Pressure & 0.991 & 0.979 & 1.003 & .123 \\
\hline & Systolic Blood Pressure & 0.999 & 0.991 & 1.006 & .776 \\
\hline & Temperature & 0.951 & 0.818 & 1.105 & .500 \\
\hline & Pulse Rate & 1.008 & 1.001 & 1.015 & $<.05$ \\
\hline & Black/African American Race & 0.880 & 0.688 & 1.126 & .307 \\
\hline & Hispanic/Latino Ethnicity & 1.134 & 0.875 & 1.469 & .345 \\
\hline & Days to Follow Up & 0.939 & 0.930 & 0.949 & $<.0001$ \\
\hline & Female Sex & 1.064 & 0.852 & 1.345 & .608 \\
\hline & Passive Smoking & 0.778 & 0.433 & 1.398 & .398 \\
\hline & Quit Smoking & 0.966 & 0.728 & 1.282 & .812 \\
\hline & Current Smoker & 0.775 & 0.597 & 1.011 & .059 \\
\hline \multirow{13}{*}{$31-60$ days $(\mathrm{N}=368)$} & Age & 0.999 & 0.992 & 1.006 & .788 \\
\hline & BMI & 0.997 & 0.983 & 1.011 & .572 \\
\hline & Diastolic Blood Pressure & 0.991 & 0.977 & 1.005 & .195 \\
\hline & Systolic Blood Pressure & 0.999 & 0.990 & 1.008 & .817 \\
\hline & Temperature & 0.893 & 0.749 & 1.065 & .207 \\
\hline & Pulse Rate & 1.012 & 1.004 & 1.020 & $<.01$ \\
\hline & Black/African American Race & 0.971 & 0.732 & 1.289 & .837 \\
\hline & Hispanic/Latino Ethnicity & 0.989 & 0.725 & 1.350 & .942 \\
\hline & Days to Follow Up & 0.970 & 0.962 & 0.978 & $<.0001$ \\
\hline & Female Sex & 0.903 & 0.683 & 1.194 & .465 \\
\hline & Passive Smoking & 1.037 & 0.546 & 1.969 & .915 \\
\hline & Quit Smoking & 0.888 & 0.630 & 1.251 & .498 \\
\hline & Current Smoker & 0.873 & 1.555 & 1.186 & .378 \\
\hline \multirow{13}{*}{$61-90$ days $(\mathrm{N}=262)$} & Age & 0.997 & 0.989 & 1.005 & .484 \\
\hline & BMI & 1.000 & 0.986 & 1.016 & .944 \\
\hline & Diastolic Blood Pressure & 0.988 & 0.972 & 1.003 & .126 \\
\hline & Systolic Blood Pressure & 1.006 & 0.996 & 1.016 & .219 \\
\hline & Temperature & 0.830 & 0.680 & 1.014 & .067 \\
\hline & Pulse Rate & 1.013 & 1.004 & 1.022 & $<.01$ \\
\hline & Black/African American Race & 1.058 & 0.775 & 1.444 & .723 \\
\hline & Hispanic/Latino Ethnicity & 0.766 & 0.529 & 1.109 & .158 \\
\hline & Days to Follow Up & 0.986 & 0.980 & 0.992 & $<.0001$ \\
\hline & Female Sex & 0.791 & 0.570 & 1.097 & .160 \\
\hline & Passive Smoking & 0.179 & 0.043 & 0.751 & $<.05$ \\
\hline & Quit Smoking & 0.675 & 0.453 & 1.005 & .053 \\
\hline & Current Smoker & 0.725 & 0.515 & 1.019 & .064 \\
\hline
\end{tabular}

Increased days between initial hospital encounter and followup visit at a primary care facility were found to be associated with lower risk of readmission within 30,60, and 90 days when compared to patients who were not readmitted within 180 days. These findings are in disagreement with the small amount of research that has previously investigated the effects of follow-up time on early all-cause readmission. In their 2010 study of patients with heart failure above the age of 65 , Hernandez et al. report an association between early follow-up visit (within 7 days of discharge) and decreased risk of 30-day all-cause readmission. ${ }^{[24]}$ As has been previously stated, our study is novel because it was conducted in a socioeconomically disadvantaged patient population. This low-income patient population may contribute to the divergence of our results from those of Hernandez et al. ${ }^{[24]}$ Study authors have reported that socioeconomically disadvantaged 
patients have an increased propensity for missing scheduled primary care appointments and often do not visit their physician unless their disease has progressed significantly. ${ }^{[25]}$ Low SES patients in this study who did follow up with their physician promptly after hospitalization, then, may have done so because their illness had worsened rapidly. Such disease progression would predispose these patients to hospitalization, leading to the association between early follow-up and increased readmission observed in our analysis. It is likely that the benefits reported by Hernandez et al. of patient education and care coordination that accompany early follow up are still applicable to low-income patient populations. ${ }^{\text {[24] }}$ Our findings suggest that in order for these benefits to result in readmission reduction in these populations, methods must be found to ensure early follow-up times in all patients regardless of patient perception or disease progression.

Status as a passive smoker was also found to be associated with lower readmission risk between 60 and 90 days when compared to patients who did not experience readmission within 180 days. Past research on the association between smoking status and readmission rates has produced equivocal results. ${ }^{[26-34]}$

Many studies have examined commonly collected demographic variables. It has been reported that increasing age could potentially serve as a predictor of all-cause hospital readmissions, especially in patients over the age of $65 .{ }^{[14,35]}$ Race and ethnicity have also been reported to be potential predictors of all-cause readmission risk, with African American and Hispanic patients facing a higher risk of early readmission than their white counterparts. ${ }^{[35,36]}$ Additionally, hospitals serving primarily ethnic and racial minority patient groups experience elevated readmission rates. ${ }^{[15,16]}$ Mixed results have been procured for sex as a variable associated with readmissions, with some studies finding elevated risk of 30-day readmission in females, ${ }^{[26,31]}$ and others finding the same risk elevation in males. ${ }^{[35]}$ Contrary to the positive findings of previous researchers, in the current study we found no statistically significant differences in hospital readmission rates in our demographic variables. The demographic variables of age and female sex were not found to be significant predictors of 30-, 60-, or 90-day readmission, which is not out of character with the unfixed body of literature. ${ }^{[11,14,26-28,31,35,37]}$

Several clinical variables showed no association with an increased risk of 30-, 60-, or 90-day all-cause readmission, consistent in part with the equivocal findings of the literature. Certain study authors have reported elevated blood pressure to be predictive of readmission in patients who had spent time in the ICU, ${ }^{[21]}$ whereas other studies have reported that readmitted patients are more likely to have low blood pressure upon admission. ${ }^{[22]}$ Our study demonstrated no relationship between blood pressure and hospital readmission rates. Body mass index (BMI) has also been examined, with a BMI above $60 \mathrm{~kg} / \mathrm{m}^{2}$ found to be associated with 30-day readmissions in a 2014 study of gastric bypass patients. ${ }^{[38]}$ We found no relationship between 30-, 60-, or 90- day readmission and BMI; however, our mean BMI $\left(31.41 \pm 9.39 \mathrm{~kg} / \mathrm{m}^{2}\right)$ is noticeably smaller than that of Tayne et al. ${ }^{[38]}$ Contrary to a previous study, ${ }^{[21]}$ we did not find body temperature to be a predictor of early hospital readmission. The inability of the clinical variables BMI, systolic blood pressure, and diastolic blood pressure to predict early readmission also supported in part the indeterminate findings of past studies. ${ }^{[11,21,22,27,31,38]}$

There did exist some limitations to the design of this study. Smoking status was measured as a self-identified variable, creating the potential for self-reporting bias. The small percentage of passive smokers in the study and relative unpredictability of 90-day readmission further limit the interpretation passive smoking findings. The small number of patients reporting as passive smokers makes analysis of the risk associated with passive smoking variable and could have led to the anomalous results of this study. With greater lengths of time, there is an increased probability of latent variables influencing the result. Additionally, the calculation of days to follow up visit only included the time between the initial hospital encounter and the follow-up visit with the physician, and did not report the time between hospital discharge and follow up. Because of this limitation, the reported days to follow up serve only as a proxy measure for the actual time between hospital discharge and patient visit to a primary care facility, though the variable remains an important measure to ascertain.

Despite these limitations, the results of the current study still provide evidence for the usefulness of certain variables in identifying patients at risk of early hospital readmission within a socioeconomically disadvantaged population. The identification of patients with elevated heart rate, passive smokers, and the number of days to follow-up may allow healthcare providers to develop more effective treatment plans and discharge strategies to reduce the likelihood of unforeseen readmission. Among these strategies should be an increased focus on ensuring that patients adhere to scheduled follow-up visits with their physician to mitigate the risk of experiencing early hospital readmission. These findings are novel and provide healthcare providers with further tools to identify at-risk patients in a socioeconomically disadvantaged population. Further study should examine the potential use of other readily collected clinical variables and laboratory tests to identify readmission risk in underserved patient populations. The continued evaluation of such methods of 
readmission reduction will allow healthcare institutions to reduce costs and increase the overall quality of care provided to patients.

\section{CONFLICTS OF INTEREST Disclosure}

The authors declare they have no conflicts of interest.

\section{REFERENCES}

[1] Evans M. Cost growth projected to climb; Can ACA initiatives slow it down? Mod Healthc. 2014; 44(36): 8-9.

[2] Rice T, Unruh LY, Rosenau P, et al. Challenges facing the United States of America in implementing universal coverage. Bull World Health Organ. 2014; 92(12): 894-902. PMid: 25552773. https: //doi.org/10.2471/BLT.14.141762

[3] Kiefe C, Allison JJ, de Lissovoy G. Predicting hospital readmission: different approaches raise new questions about old issues. Med Care. 2013; 51(1): 11-12. PMid: 23222466. https ://doi.org/10.109 7/MLR.0b013e3182780afb

[4] Cloonan P, Wood J, Riley JB. Reducing 30-day readmissions: health literacy strategies. J Nurs Adm. 2013; 43(7-8): 382-387. PMid: 23892303. https://doi.org/10.1097/NNA.0b013e31829d60 82

[5] Vest JR, Gamm LD, Oxford BA, et al. Determinants of preventable readmissions in the United States: a systematic review. Implement Sci IS. 2010; 5: 88. PMid: 21083908. https ://doi.org/10.118 6/1748-5908-5-88

[6] Hospital Readmission Reduction Program. CMS.gov. 2015. Available from: https://www.cms.gov/Medicare/Quality-I nitiatives-Patient-Assessment-Instruments/Value-B ased-Programs/HRRP/Hospital-Readmission-Reduction -Program.html

[7] FY2015-Final-Rule-Regulations. CMS.gov. 2015. Available from: https://www.cms.gov/Medicare/Medicare-Fee-for-Ser vice-Payment/AcuteInpatientPPS/FY2015-IPPS-Final-R ule-Home-Page-Items/FY2015-Final-Rule-Regulations .html?DLPage=1\&DLSort=0\&DLSortDir=ascending

[8] Postel M, Frank PN, Barry T, et al. The cost of preventing readmissions: why surgeons should lead the effort. Am Surg. 2014; 80(10): 1003-1006. PMid: 25264648.

[9] Silverstein MD, Qin H, Mercer SQ, et al. Risk factors for 30day hospital readmission in patients $\geq 65$ years of age. Proc Bayl Univ Med Cent. 2008; 21(4): 363-372. PMid: 18982076. https: //doi.org/10.1080/08998280.2008.11928429

[10] Bikdeli B, Wayda B, Bao H, et al. Place of residence and outcomes of patients with heart failure: analysis from the telemonitoring to improve heart failure outcomes trial. Circ Cardiovasc Qual Outcomes. 2014; 7(5): 749-756. PMid: 25074375. https: //doi.org/10.1161/CIRCOUTCOMES.113.000911

[11] Krumholz HM, Chen YT, Wang Y, et al. Predictors of readmission among elderly survivors of admission with heart failure. Am Heart J. 2000; 139(1 Pt 1): 72-77. https://doi.org/10.1016/S0002-8 703(00) 90311-9

[12] Rubin DJ, Handorf EA, Golden SH, et al. Development And Validation Of A Novel Tool To Predict Hospital Readmission Risk Among Patients With Diabetes. Endocr Pract Off J Am Coll Endocrinol Am Assoc Clin Endocrinol. 2016; 22(10): 1204-1215. https://doi.org/10.4158/E161391.OR

[13] Bernheim SM, Spertus JA, Reid KJ, et al. Socioeconomic disparities in outcomes after acute myocardial infarction. Am Heart J. 2007; 153(2): 313-319. https://doi .org/10.1016/j.ahj . 2006.10. 037

Published by Sciedu Press
[14] Fuller RL, Atkinson G, McCullough EC, et al. Hospital readmission rates: the impacts of age, payer, and mental health diagnoses. J Ambulatory Care Manage. 2013; 36(2): 147-155. https : //doi.org/10.1097/JAC.0b013e3182866c1c

[15] McHugh MD, Carthon JMB, Kang XL. Medicare Readmissions Policies and Racial and Ethnic Health Disparities: A Cautionary Tale. Policy Polit Nurs Pract. 2010; 11(4): 309-316. https : //doi.org/10.1177/1527154411398490

[16] Tsai TC, Orav EJ, Joynt KE. Disparities in surgical 30-day readmission rates for Medicare beneficiaries by race and site of care. Ann Surg. 2014; 259(6): 1086-1090. https://doi.org/10.1097/SL A. 0000000000000326

[17] Shah T, Churpek MM, Coca PM, et al. Understanding why patients with COPD get readmitted: a large national study to delineate the Medicare population for the readmissions penalty expansion. Chest. 2015; 147(5): 1219-1226. https://doi.org/10.1378/chest. 14-2181

[18] Feemster LC, Au DH. Penalizing hospitals for chronic obstructive pulmonary disease readmissions. Am J Respir Crit Care Med. 2014; 189(6): 634-639. https://doi.org/10.1164/rccm.201308-1 $541 \mathrm{PP}$

[19] Health Systems Strengthening Glossary. WHO.int. Accessed February 27, 2017. Available from: http://www.who.int/healthsy stems/hss_glossary/en/

[20] Jensen MT, Suadicani P, Hein HO, et al. Elevated resting heart rate, physical fitness and all-cause mortality: a 16-year follow-up in the Copenhagen Male Study. Heart Br Card Soc. 2013; 99(12): 882-887. https://doi.org/10.1136/heartjnl-2012-303375

[21] Fialho AS, Cismondi F, Vieira SM, et al. Data mining using clinical physiology at discharge to predict ICU readmissions. Expert Syst Appl. 2012; 39(18): 13158-13165. https://doi.org/10.1016/ j.eswa.2012.05.086

[22] Eapen ZJ, Reed SD, Li Y, et al. Do countries or hospitals with longer hospital stays for acute heart failure have lower readmission rates?: Findings from ASCEND-HF. Circ Heart Fail. 2013; 6(4): 727-732. https ://doi .org/10.1161/CIRCHEARTFAILURE. 112 .000265

[23] Lantz PM, House JS, Lepkowski JM, et al. Socioeconomic factors, health behaviors, and mortality: results from a nationally representative prospective study of US adults. JAMA. 1998; 279(21): 17031708. PMid: 9624022 . https://doi.org/10.1001/jama.279.2 1.1703

[24] Hernandez AF, Greiner MA, Fonarow GC, et al. Relationship between early physician follow-up and 30-day readmission among Medicare beneficiaries hospitalized for heart failure. JAMA. 2010; 303(17): 1716-1722. https://doi.org/10.1001/jama.2010 533

[25] Sharp DJ, Hamilton W. Non-attendance at general practices and outpatient clinics. BMJ. 2001; 323(7321): 1081-1082. https: //doi.org/10.1136/bmj.323.7321.1081

[26] Robinson S, Howie-Esquivel J, Vlahov D. Readmission risk factors after hospital discharge among the elderly. Popul Health Manag. 2012; 15(6): 338-351. https://doi.org/10.1089/pop. 2011.0 095 
[27] Dallal RM, Trang A. Analysis of perioperative outcomes, length of hospital stay, and readmission rate after gastric bypass. Surg Endosc. 2012; 26(3): 754-758. https://doi.org/10.1007/s00464-011 $-1947-z$

[28] Kilkenny MF, Longworth M, Pollack M, et al. Factors associated with 28-day hospital readmission after stroke in Australia. Stroke. 2013; 44(8): 2260-2268. https://doi.org/10.1161/STROKEAH A. 111.000531

[29] Mlodinow AS, Ver Halen JP, Lim S, et al. Predictors of readmission after breast reconstruction: a multi-institutional analysis of 5012 patients. Ann Plast Surg. 2013; 71(4): 335-341. https: //doi.org/10.1097/SAP.0b013e3182a0df25

[30] Beaulieu RJ, Grimm JC, Lyu H, et al. Rates and predictors of readmission after minor lower extremity amputations. J Vasc Surg. 2015; 62(1): 101-105. https://doi.org/10.1016/j.jvs.2015.02. 021

[31] McPhee JT, Nguyen LL, Ho KJ, et al. Risk prediction of 30-day readmission after infrainguinal bypass for critical limb ischemia. J Vasc Surg. 2013; 57(6): 1481-1488. https ://doi.org/10.1016/ j.jvs.2012.11.074

[32] Rambachan A, Matulewicz RS, Pilecki M, et al. Predictors of readmission following outpatient urological surgery. J Urol. 2014; 192(1): 183-188. https://doi.org/10.1016/j.juro.2013.12.053
[33] Sales VL, Ashraf MS, Lella LK, et al. Utilization of trained volunteers decreases 30-day readmissions for heart failure. J Card Fail. 2013; 19(12): 842-850. https://doi.org/10.1016/j.cardfa il.2013.10.008

[34] Brener ND, Billy JOG, Grady WR. Assessment of factors affecting the validity of self-reported health-risk behavior among adolescents: evidence from the scientific literature. J Adolesc Health Off Publ Soc Adolesc Med. 2003; 33(6): 436-457. https://doi.org/10.101 6/S1054-139X (03) 00052-1

[35] Navarro AE, Enguídanos S, Wilber KH. Identifying risk of hospital readmission among Medicare aged patients: an approach using routinely collected data. Home Health Care Serv Q. 2012; 31(2): 181-195. https://doi .org/10.1080/01621424.2012.681561

[36] Joynt KE, Orav EJ, Jha AK. Patient race, site of care, and 30-day readmission rates among elderly Americans. Jama. 2011; 305(7): 675-681. https://doi.org/10.1001/jama.2011.123

[37] Iloabuchi TC, Mi D, Tu W, et al. Risk factors for early hospital readmission in low-income elderly adults. J Am Geriatr Soc. 2014; 62(3): 489-494. https://doi.org/10.1111/jgs. 12688

[38] Tayne S, Merrill CA, Shah SN, et al. Risk factors for 30-day readmissions and modifying postoperative care after gastric bypass surgery. J Am Coll Surg. 2014; 219(3): 489-495. https ://doi . org/10.1 $016 / j \cdot j$ amcollsurg. 2014.03.054 